\title{
Ultra-Microporous Membrane Separation Using Toluene to Simulate Tar-Containing Gases
}

\author{
Beshan Deonarine ${ }^{1}$, Guozhao $\mathrm{Ji}^{2}$, Simon Smart ${ }^{2}$, João C. Diniz da Costa ${ }^{2}$, Graham Reed ${ }^{1 *}$, Marcos \\ Millan $^{1}$
}

${ }^{1}$ Department of Chemical Engineering, Imperial College London, South Kensington Campus, London SW7 2AZ, UK.

${ }^{2}$ The University of Queensland, FIM ${ }^{2}$ Lab - Functional Interfacial Materials and Membranes Laboratory, School of Chemical Engineering, Brisbane Qld4072, Australia.

\section{Corresponding Author}

*G. Reed. Tel: +447578237296; fax: +442075945638; E-mail: graham.reed1@imperial.ac.uk

\begin{abstract}
This study investigates the performance of ultra-microporous cobalt oxide silica membranes for processing simulated gas streams containing toluene as a model tar compound in gasification. The performance of the membranes was initially investigated for $\mathrm{He}$ (simulating $\mathrm{H}_{2}$ ), $\mathrm{CO}_{2}, \mathrm{~N}_{2}$ and $\mathrm{Ar}$ in a range of temperatures. Subsequently, toluene was added to a gas mixture containing He and tested to
\end{abstract}


simulate the effect of toluene as a tar compound in gasification. The membranes delivered molecular sieving features, showing activated transport as the permeation of the smaller molecular gas He increased with temperature whilst the permeation decreased for the other larger molecular gases. Prior to toluene exposure, He permeance increased by almost twofold from $3.6 \times 10^{-8}$ to $7.1 \times 10^{-8} \mathrm{~mol} \mathrm{~m}^{-2} \mathrm{~s}^{-}$

${ }^{1} \mathrm{~Pa}^{-1}$ as the temperature was raised from 50 to $200{ }^{\circ} \mathrm{C}$. Under a feed gas containing $0.24 \mathrm{~mol} \%$ toluene, He permeance decreased by an average value of $17 \%$. Upon regeneration of the membrane by heat, He permeance was not fully recovered, a clear indication of tar fouling. A toluene balance calculation showed toluene being retained by the membrane.

Keywords: Gas separation; membranes; ultra-micropores; tars.

\section{Introduction}

The impact of fossil-fuel use on climate change has led to the development of carbon capture and storage (CCS) technologies and a rapid increase in the use of renewables for power generation. Electricity can be produced using biomass by direct combustion in a thermal power plant, or by gasification to produce a secondary fuel (or energy carrier) which may then be fed to a power plant for the generation of electricity [1] or used as feedstock for fuel production [2, 3]. Hence, biomass is an attractive option in the energy mix, as $\mathrm{CO}_{2}$ emissions during the conversion of biomass to electricity are roughly matched by that sequestered during biomass growth. Therefore, biomass can be considered carbon neutral in its lifecycle [4].

Biomass gasification results in the production of syngas, containing mainly $\mathrm{CO}$ and $\mathrm{H}_{2}$ plus some contaminants. The $\mathrm{CO}$ can be further reacted with water to produce more $\mathrm{H}_{2}$ and $\mathrm{CO}_{2}$ via the water gas shift reaction (WGSR). Biomass gasification processes also produce tars as contaminants which pose a 
major technical obstacle in implementing this technology. Tars are a complex mixture of condensable hydrocarbons, which includes single ring to complex polynuclear aromatic hydrocarbons along with other oxygen-containing compounds [5]. Tars present a problem to downstream use of the gas, as they can condense to cause fouling [6] and coke formation in equipment [7] and upgrading catalysts. Tar generation is also common in coal gasification processes $[8,9]$. The raw syngas from a circulating bed gasifier can be expected to contain around $15 \mathrm{~g} \mathrm{Nm}^{-3}$ of tar [10], and with downstream processing and wet scrubbing such as absorption/adsorption [11] or catalytic decomposition [12, 13], this may be reduced to around $1 \mathrm{~g} \mathrm{Nm}^{-3}$.

$\mathrm{H}_{2}$ is a gas of major industrial interest due to its high energy content for power production, with an added benefit as a feedstock for fuel production or as fuel in fuel cell systems. In principle, $\mathrm{H}_{2}$ can be separated after the water gas shift reactors using conventional gas separation technologies such as solvent stripping or adsorption. However, these technologies require gas streams preferably closer to ambient temperatures to operate efficiently. As the water gas shift reaction is exothermic with reactors operating between 200 and $600{ }^{\circ} \mathrm{C}$, cooling down large volume of gases for cold wet scrubbing for the final $\mathrm{CO}_{2} / \mathrm{H}_{2}$ separation is energy intensive [14].

To address this problem, several groups have developed metal/alloys [15-18] or microporous ceramic membranes based on silica [19-22] and zeolites [23-25] for $\mathrm{H}_{2}$ separation at high temperatures. In addition, membrane reactor configurations have been investigated, where WGSR catalysts and membranes are integrated into a single process unit for $\mathrm{H}_{2}$ separation and the subsequent WGSR shifting, overcoming equilibrium limitations at the same time [25-29]. In general terms, metal oxide silica membranes have shown to be thermally stable [30] and deliver high $\mathrm{H}_{2}$ purities of $>98 \mathrm{~mol} \%$ for processing syngas downstream from the water gas shift reactors [31]. 
Whilst the bulk of the work published in literature has been confined to the use of pure gases only, further research is warranted to understand the effects of tars on gas mixture separation. To this end, this work investigates the transport of gases through microporous cobalt oxide silica membranes in gas streams containing pure gases as well as a condensable hydrocarbon (toluene) as the major component of tars from biomass or coal gasification. The membrane was exposed to a gas mixture at a range of temperatures, and gas permeation was investigated prior, during and after exposure to toluene, to simulate tar-gas mixtures.

\section{Experimental}

\subsection{Membrane preparation and characterisation}

Cobalt oxide silica sols were prepared according to an adapted sol-gel procedure published elsewhere [32]. In this procedure, cobalt nitrate hexahydrate $\mathrm{Co}\left(\mathrm{NO}_{3}\right)_{2} \cdot 6 \mathrm{H}_{2} \mathrm{O}$ was dissolved in a hydrogen peroxide solution (30 wt $\% \mathrm{H}_{2} \mathrm{O}_{2}$ in water) and placed in an ice-cooled bath. Ethanol (EtOH) and tetraethyl orthosilicate (TEOS) were then added to the sol and stirred for 3 hours to reach a final molar ratio of TEOS: EtOH: $\mathrm{H}_{2} \mathrm{O}_{2}=4: 255: 5$ and $\mathrm{Si}: \mathrm{Co}=5: 1$. The resultant sol was used to coat the outer shell of commercial tubular alumina tubes (supplied by Energy Research Centre of the Netherlands) in a custom dip-coater. The alumina tubes consisted of $\alpha$-alumina substrate (inner shell) and $\gamma$-alumina interlayer, $20 \mathrm{~cm}$ in length and $1.4 \mathrm{~cm}$ in diameter. The tubes were immersed in the sol for $1 \mathrm{~min}$ with an immersion/withdrawal speed of $10 \mathrm{~cm} \mathrm{~min}^{-1}$. Subsequently, the coated tubes were calcined in air at $630^{\circ} \mathrm{C}$ for 2 hours with a heating/cooling rate of $1{ }^{\circ} \mathrm{C} \mathrm{min}^{-1}$. This process was repeated for each sequential membrane layer. The final membrane had 4 coated layers. The membrane morphology was examined under a FESEM Jeol 7001F scanning electron microscope with a hot (Schottky) electron gun at an acceleration voltage of $10 \mathrm{kV}$. 
The inner shells of the membranes were then pressurized to $0.2 \mathrm{MPa}$ and the membranes were immersed in a water bath at room temperature to verify if there were any defects. Defect-free membranes were tested for single gas permeation $\left(\mathrm{He}, \mathrm{CO}_{2}, \mathrm{Ar}\right.$ and $\left.\mathrm{N}_{2}\right)$ from 100 to $500{ }^{\circ} \mathrm{C}$ in a dead-end volume experimental rig as described elsewhere [32]. The membranes were tested at the University of Queensland in Australia using a steel pressurised vessel. Special graphite seals [33] were used to seal the membrane tubes, thus allowing high temperature permeation tests at a feed pressure of $300 \mathrm{kPa}$. Additional defect-free membranes were tested in a simulated syngas atmosphere.

\section{2 $\quad$ Simulated syngas testing}

The simulated syngas separation experimental work was carried out at Imperial College London in the United Kingdom. He (an inert gas) was chosen instead of $\mathrm{H}_{2}$, as it has a similar kinetic diameter $(0.26$ versus $0.29 \mathrm{~nm})$. He is a non-explosive gas, thus conforming with safe experimental procedures. Further, both $\mathrm{He}$ and $\mathrm{H}_{2}$ gases have been reported to exhibit permeances of the same order of magnitude through micro-porous silica membranes [34, 35]. With respect to tar compounds, benzene, toluene and naphthalene have been used as tar models for catalytic studies [36] and for elucidating the interactions between tars and solid oxide fuel cell anodes [37]. In this work, toluene was chosen as the model tar compound as single ring aromatic compounds may account for approximately two thirds of the percentage weight of tars in the product gas [38]. Therefore, toluene should prove to be a good approximation to the interactions between membranes and an actual tar mixture produced from biomass gasification $[39,40]$. A point of interest here is that the effect of single-ring aromatics tars on solid oxide fuel cell anodes were found to represent an even more challenging problem than the actual tars [41]. Moreover, the choice of toluene avoids the handling and safety issues associated with naphthalene and benzene. The investigation was conducted using He and toluene as model compounds to simulate the system of interest. 
A schematic of the membrane test rig is shown in Fig. 1. He gas was continuously supplied to the feed line. Liquid toluene $\left(\mathrm{C}_{7} \mathrm{H}_{8}\right)$ was injected at a constant rate into the feed line by a syringe pump injection system, where it evaporated and mixed with the He feed to create a nominal toluene concentration of $10 \mathrm{~g} \mathrm{Nm}^{-3}(0.24 \mathrm{~mol} \%)$. The toluene/He mixture was then directed to the membrane module containing a microporous cobalt oxide silica membrane, which was housed in a vertical tubular electric furnace heated to the selected operating temperature. Gas permeation tests were limited to 200 ${ }^{\circ} \mathrm{C}$ by the maximum working temperature of the membrane Viton seals. Toluene was sampled from both permeate and retentate streams by batch condensation and scrubbing in chilled heptane, and the amount collected determined from the intensity of fluorescence at $285 \mathrm{~nm}$ using a Perkin Elmer LS55 luminescence spectrometer.

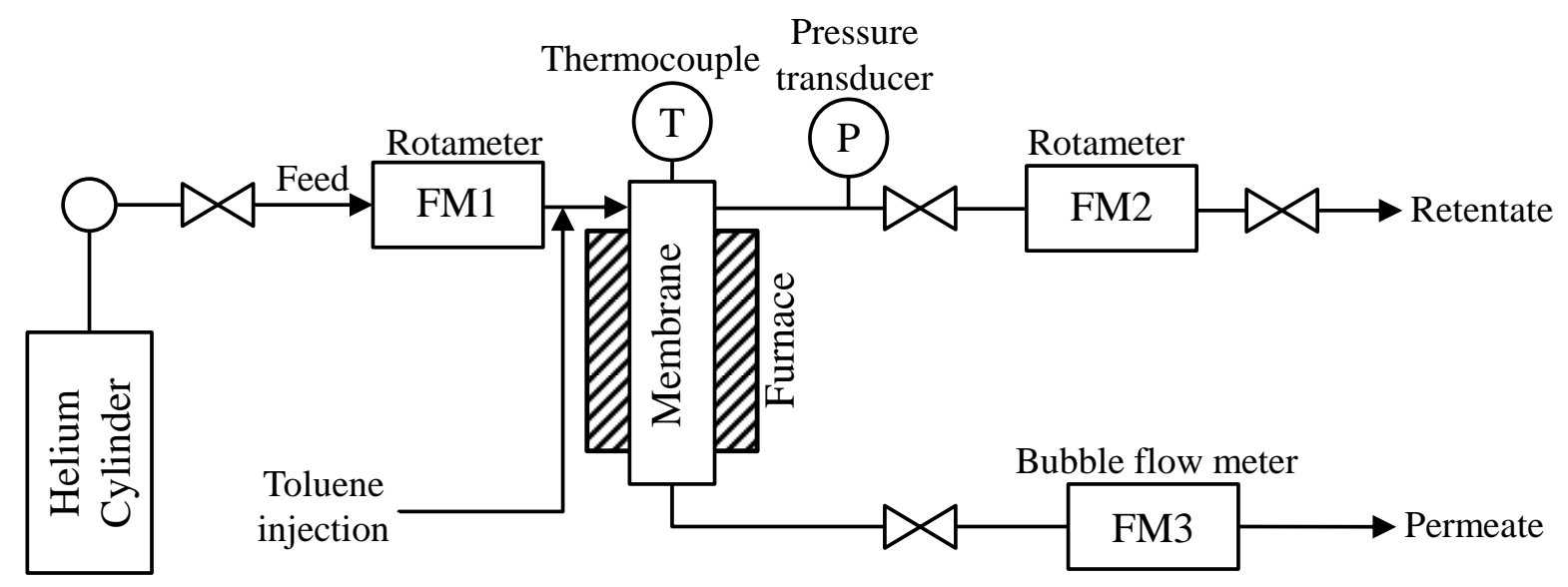

Fig. 1. Schematic of membrane test rig

The experimental procedure consisted of five phases. In Phase 1, the membrane was activated at 150 ${ }^{\circ} \mathrm{C}$ in $\mathrm{He}$ for one hour; this was carried out to clean the membrane from any adsorbed atmospheric gases and moisture. Phase 2 consisted mainly of single gas permeation experiments prior to exposure to 
the simulated gas mixture. The permeation of He was measured by a bubble flowmeter. He feed flowrate of $30 \mathrm{~mL} \mathrm{~min}^{-1}$ was constantly maintained and the membranes were tested at temperatures of $50,100,150$ and $200{ }^{\circ} \mathrm{C}$ and a total feed pressure of $130 \mathrm{kPa}$. In Phase 3, toluene was injected in the feed line containing $\mathrm{He}$ at a concentration of $10 \mathrm{~g} \mathrm{Nm}^{-3}$. Subsequently, gas permeation was carried out at the same conditions of Phase 2. Membrane regeneration was conducted in Phase 4, where the membrane was heated to $150{ }^{\circ} \mathrm{C}$ in pure $\mathrm{He}$ for one hour; the moderate regeneration temperature was necessary to minimize the risk of prematurely damaging the polymer $\mathrm{O}$ ring seals used to seal the experimental rig. Finally, a repeat of the single gas permeation measurements at the same temperatures was conducted in Phase 5 in a similar fashion as in Phase 2.

\section{Results and discussions}

A cross section SEM micrograph of a cobalt oxide silica membrane is shown in Fig. 2. The cobalt oxide silica top layer contains a very thin cobalt oxide silica layer $\sim 250 \mu \mathrm{m}$ thick as reported elsewhere [42]. The top layer was coated on two $\gamma$-alumina interlayers of total $\sim 3 \mu \mathrm{m}$ depth, with the required smooth surface for thin film deposition. Subsequently, there are two further interlayers $\sim 30 \mu \mathrm{m}$ thick each coated on a substrate of $\alpha$-alumina particles. In this system, the pore size on the top layer is generally well below the resolution capability of SEM equipment, whilst the pore size of the interlayers increased towards the substrate, thus forming an asymmetric structure. 

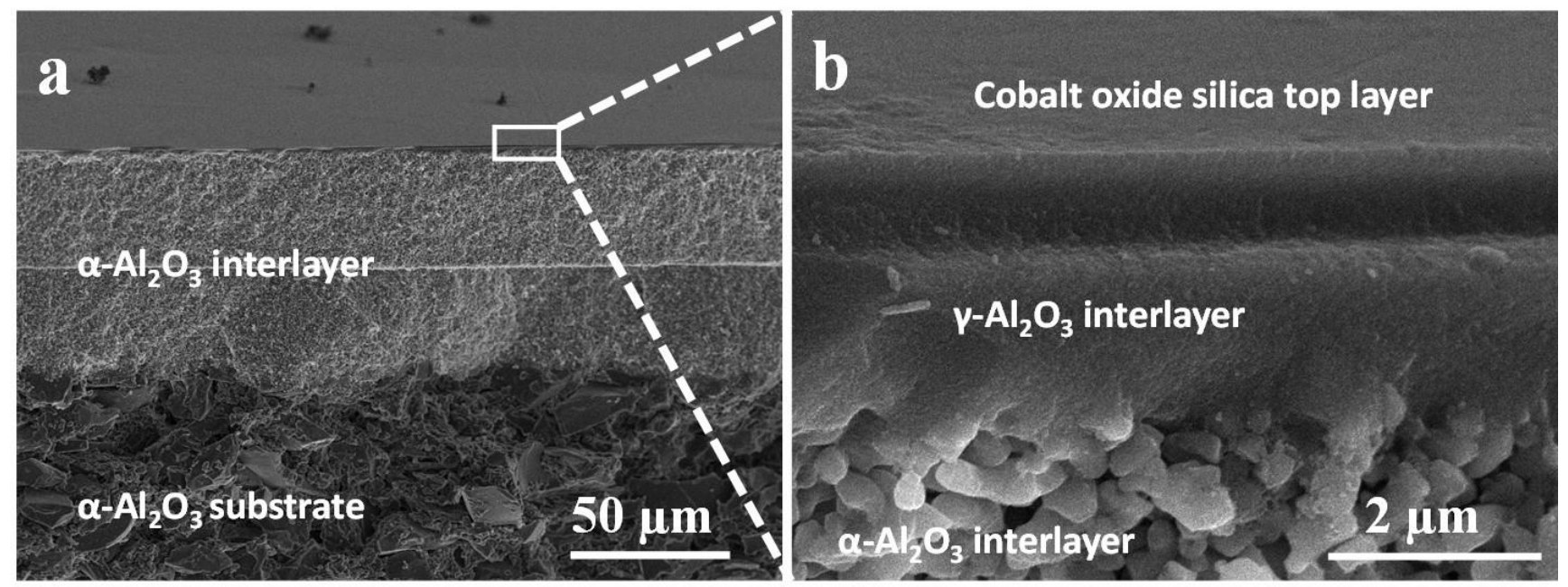

Fig. 2. SEM micrograph of a cross section profile of a cobalt oxide silica membrane.

Fig. 3 shows single gas permeation results up to $500{ }^{\circ} \mathrm{C}$, for membrane samples retained and examined at the University of Queensland. The permeance of the gas with the smaller kinetic diameter $\mathrm{He}(2.6 \AA)$ increased with temperature while that of the larger molecular gases, $\mathrm{CO}_{2}(3.3 \AA), \mathrm{N}_{2}(3.7 \AA)$ and $\operatorname{Ar}(3.4 \AA)$, decreased. These results are features of ultra-microporous membranes with average pore diameters between 3 and $5 \AA \AA$. Hence, these membranes are characterised by molecular sieving structures, delivering a temperature dependent gas transport, also known as activated transport and described by the following equation derived from Barrer's diffusion model [43] through porous structures:

$$
J_{x}=-D_{0} K_{0} \exp \left(\frac{Q_{s t}-E_{m}}{R T}\right) \frac{d p}{d x}
$$

where $\mathrm{J}$ is the gas flux $\left(\mathrm{mol} \mathrm{m} \mathrm{m}^{-2} \mathrm{~s}^{-1}\right), D_{o}$ and $K_{o}$ are temperature independent proportionality constants, $E_{m}$ is the mobility energy or the activation energy for diffusion $\left(\mathrm{J} \mathrm{mol}^{-1}\right), Q_{s t}$ the isosteric heat of adsorption $\left(\mathrm{J} \mathrm{mol}^{-1}\right), R$ the gas constant $\left(\mathrm{J} \cdot \mathrm{mol}^{-1} \mathrm{~K}^{-1}\right), T$ the absolute temperature $(\mathrm{K})$ for a $d p / d x$ of pressure $p(\mathrm{~Pa})$ over a membrane thickness $x(\mathrm{~m})$. Gas adsorption on silica films is generally constant as a function of pressure, thus in the low coverage of Henry's regime except that $\mathrm{CO}_{2}$ shows minor 
non-linearity [44]. Due to the stronger adsorption of $\mathrm{CO}_{2}$ on porous silica based materials than $\mathrm{N}_{2}$ and other gases $[45,46]$, the permeance of $\mathrm{CO}_{2}$ tend to be lower than those gases with slightly larger kinetic diameters such as $\mathrm{N}_{2}$ and Ar. This has been demonstrated for a number of metal oxide silica membranes such as in this work, including niobia silica [47], cobalt oxide silica [33], hydrothermally treated cobalt oxide silica [21], and iron cobalt oxide silica [48] membranes. As He is essentialy a nonadsorbing gas at the tested conditions [49], He gave a positive apparent energy of activation whilst this apparent energy was negative for the other gases due to stronger adsorption effect. This classical behaviour of molecular sieving membranes favours gas separation at high temperatures. For instance, $\mathrm{He} / \mathrm{CO}_{2}$ permselectivity from the data shown in Fig. 3 was 56.3 at $500{ }^{\circ} \mathrm{C}$, though a much lower value of 6.7 at $100{ }^{\circ} \mathrm{C}$.

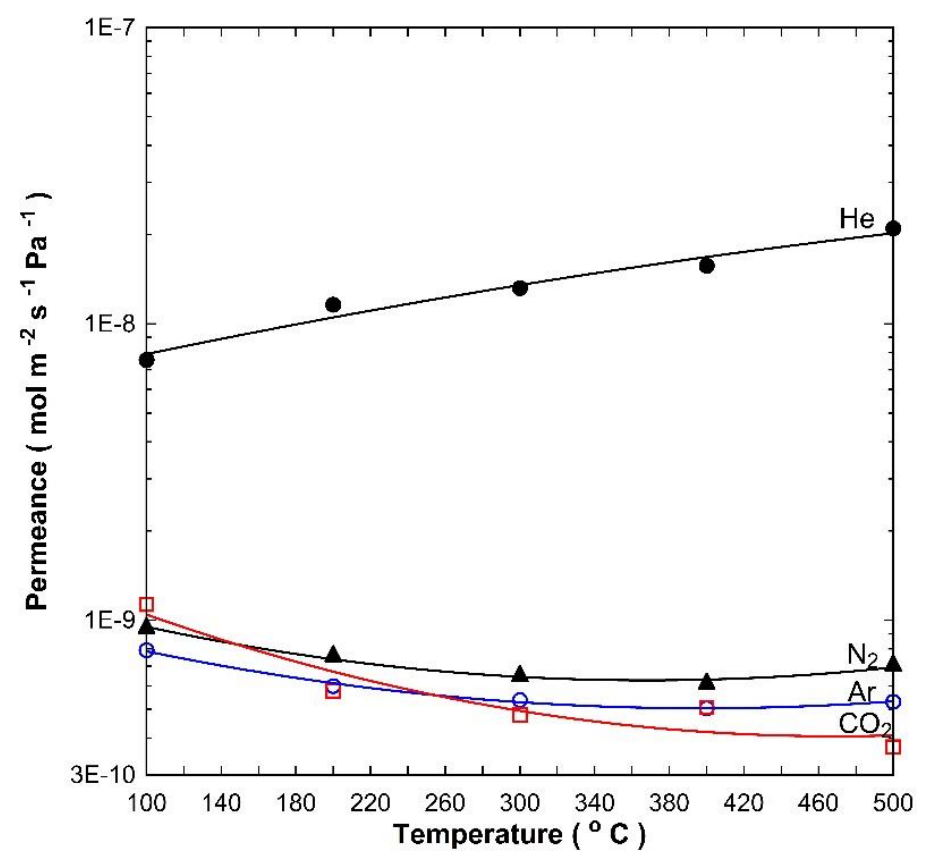

Fig. 3. Permeance $( \pm 10 \%)$ of $\mathrm{He}, \mathrm{N}_{2}, \mathrm{Ar}$ and $\mathrm{CO}_{2}$ as a function of temperature from 100 to $500{ }^{\circ} \mathrm{C}$ in single gas permeation experiments.

Fig. 4a shows the permeance of $\mathrm{He}$ at a temperature range of $50{ }^{\circ} \mathrm{C}$ to $200{ }^{\circ} \mathrm{C}$ before toluene exposure, during toluene exposure and after the regeneration of the membrane by heat treatment, 
determined for membrane samples tested at Imperial College London. Prior to toluene exposure, the permeance of $\mathrm{He}$ at $50{ }^{\circ} \mathrm{C}$ of $3.6 \times 10^{-8} \mathrm{~mol} \mathrm{~m}^{-2} \mathrm{~s}^{-1} \mathrm{~Pa}^{-1}$ increased almost twofold at $200{ }^{\circ} \mathrm{C}$ reaching 7.1 $\times 10^{-8} \mathrm{~mol} \mathrm{~m}^{-2} \mathrm{~s}^{-1} \mathrm{~Pa}^{-1}$, also following an activated transport mechanism. This molecular sieving feature can be further verified against the permeance of toluene, which is almost two orders of magnitude below that of He. Fig. 4a shows the substantially lower value of the permeance to toluene, which was almost constant at $1.0 \times 10^{-9} \mathrm{~mol} \mathrm{~m}^{-2} \mathrm{~s}^{-1} \mathrm{~Pa}^{-1}$, slightly decreasing as the temperature increased in excess of $150{ }^{\circ} \mathrm{C}$. It is important to note that the He permeance of the membrane tube tested at Imperial College London in the United Kingdom was threefold larger than the membrane tube tested at The University of Queensland in Australia. This type of permeance variation is common in silica derived membranes from the same batch, and is attributed to variations in the porous substrate morphology which tends to affect the morphology of the top silica, together with minor variations during membrane dip coating and calcination. Nevertheless, the molecular sieving structure of the different membranes are evidenced by $\mathrm{He} / \mathrm{CO}_{2}$ and $\mathrm{He} /$ toluene permselectivities at $200{ }^{\circ} \mathrm{C}$ of 20.1 and 57.57 , respectively.

For temperatures of 50, 100, 150 and $200{ }^{\circ} \mathrm{C}$ in Fig. 4a, the percentage mole fraction of toluene in the permeate stream was $0.0210,0.0174,0.0169$ and $0.014 \%$, respectively. This reduction in toluene content with temperature is due to the fact that as the temperature increased, the permeation of He likewise increased. As a result, the toluene concentration in the permeate stream decreased. It is interesting to observe that as the toluene feed composition was maintained constant at $0.24 \mathrm{~mol} \%$, the decrease in the concentration of toluene in the permeate stream as a function of temperature can be translated into a reduction of the partial pressure of toluene. Hence, the driving force, which is the toluene partial pressure difference between the feed and permeate streams, also increased with temperature. 
a

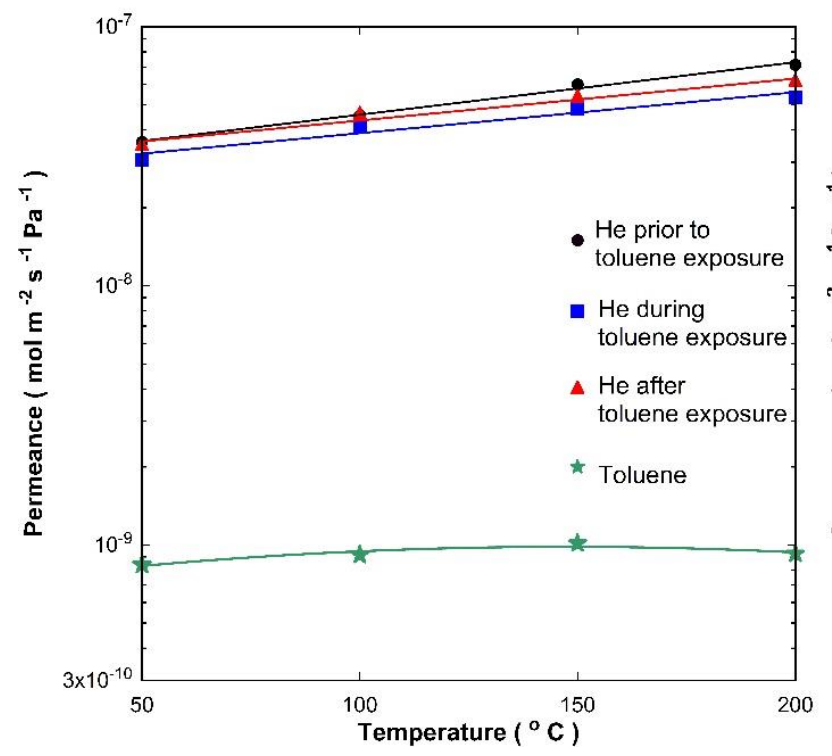

b

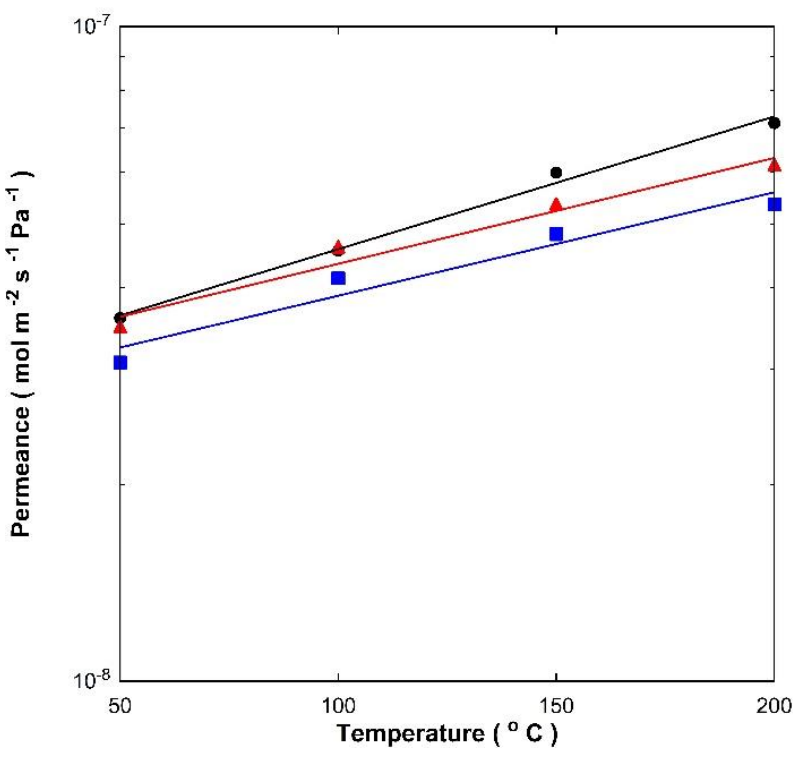

Fig. 4 (a) He and toluene permeance $( \pm 10 \%)$ and (b) He permeance as a function of temperature for before toluene exposure $(\bullet)$, during toluene exposure $(\square)$ and after membrane regeneration $(\boldsymbol{\Delta})$.

In order to provide a more meaningful visualization of the effect of toluene on He permeance as the simulated syngas in this study, the He permeances in Fig. $4 a$ are displayed in Fig. $4 b$ on a smaller yaxis scale. The exposure to toluene resulted in a He permeance reduction between 10 and $25 \%$, with an average value of $17 \%$, whilst the larger decrease occurred at higher temperatures. Upon regeneration, the membrane was tested again in pure He. The permeance to He increased, almost regaining the values obtained prior to toluene exposure at 50 and $100{ }^{\circ} \mathrm{C}$, though lower by $10-15 \%$ for the higher temperatures, 150 and $200{ }^{\circ} \mathrm{C}$. The gas stream containing toluene seems to have fouled the performance of the membrane, even after regeneration. To further understand the fouling effect of toluene, a mass balance was performed by considering the total amount of toluene injected in the feed stream, and the total amount measured in both exit lines, the permeate and retentate streams. The difference was the amount of toluene retained in the membrane.

Table 1. Toluene Loss and apparent adsorption as a function of temperature 


\begin{tabular}{|c|c|c|c|c|}
\hline Temperature $\left({ }^{\circ} \mathrm{C}\right)$ & 50 & 100 & 150 & 200 \\
\hline Loss of Toluene $^{\mathrm{a}}(\%)$ & 26.0 & 23.9 & 20.0 & 18.6 \\
\hline $\begin{array}{l}\text { Apparent Adsorption by } \\
\text { membrane }^{\mathrm{b}}\left(\mathrm{mg} \mathrm{m}^{-2}\right)\end{array}$ & 313 & 289 & 242 & 225 \\
\hline
\end{tabular}

Notes: a $\quad$ Loss of toluene by difference, as a percentage of permeate + retentate

b Loss of toluene per unit of active membrane area

Table 1 shows the results of such a toluene balance, expressed as a percentage loss and as a mass per unit area, as a function of temperature. The loss of toluene and the apparent adsorption by the membrane decreased with temperature in a manner consistent with adsorption principles, as the physical adsorption of molecules onto a solid surface reduces with increasing temperature [50]. This effect can possibly be explained by the equilibrium adsorption/condensation of toluene onto the membrane outer surface as well as within the membrane pores. In other words, as the temperature increased, the equilibrium amount of toluene adsorbed onto membrane surface or within the pore structure decreased. Even after regeneration, He permeance was not totally recovered as shown in Fig. $4 \mathrm{~b}$, thus suggesting that toluene was not totally desorbed during the regeneration process, possibly requiring higher temperatures for its removal from the membrane matrix.

Due to the morphological features of silica film structures, silica derived membranes have a pore size distribution (PSD) that can be better described by molecular probing tests, as shown in Fig. 5. The molecular probing PSD was normalized based on relative ratio of gas/vapour permeance over the permeance of He. The idealized PSD of the first membrane tested at The University of Queensland (Australia) shows that there is an abrupt reduction of the relative ratio of $\mathrm{He} / \mathrm{He}$ from 1 to $\mathrm{He} / \mathrm{CO}_{2}=0.049$, equivalent to a $\mathrm{He} / \mathrm{CO}_{2}$ permselectivity of 20.1. Small variations in $\mathrm{Ar}$ and $\mathrm{N}_{2}$ occurred, also attributed to sorption effects of these gases. The second membrane tested at Imperial 
College London (United Kingdom) shows further reduction of the relative ratio $\mathrm{C}_{7} \mathrm{H}_{8} / \mathrm{He}$ to 0.017 , a permeselectivity of 57.7. These results clearly indicate that the majority of the pore sizes which control permeation have dimensions below $3.2 \AA$. The number of pores reduced by over one order of magnitude for the diffusion of $\mathrm{CO}_{2}, \mathrm{~N}_{2}$ and Ar, and almost two orders of magnitude for the diffusion of toluene. For toluene to permeate through the membrane there might be micro-defects or percolation pathways with pore sizes larger than $6.1 \AA$. Micro-defects tend to cause parallel transport of gases, greatly reducing the permselectivity of the membranes, and leading to either Knudsen or bulk diffusion flows which reduce with temperature. This is not the case in these membranes as He permeance increases with temperature for all tests carried out. Due to the amorphous nature of ultra-microporous silica, pore sizes tend to have a tri-modal distribution peaking at 3,8 and $12 \AA$ [51]. As the cobalt oxide silica film is very thin in the region of $0.25 \mu \mathrm{m}$, there is always a probability of the larger pores being connected, thus forming a percolation pathway. Hence, it was concluded that the cobalt oxide silica matrix has a small percentage of constrictions in excess of $6.1 \AA$ which are linked together, thus allowing for the diffusion of toluene.

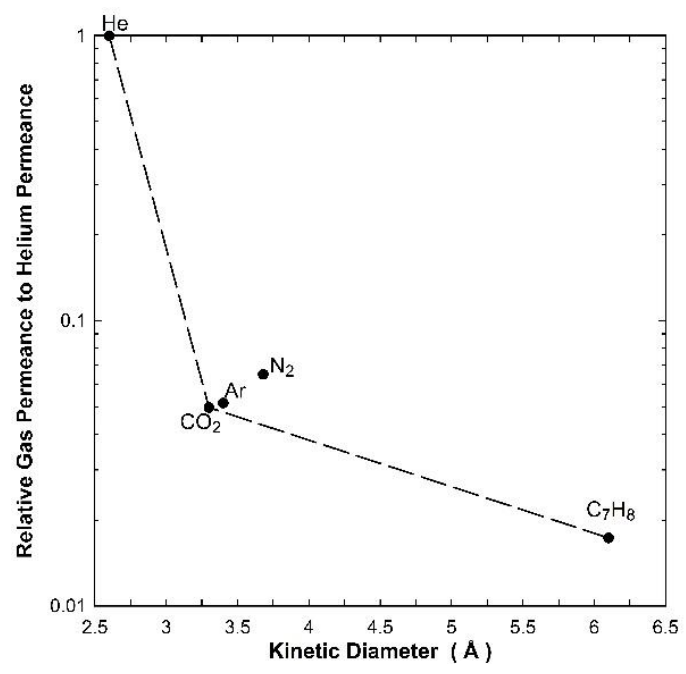


Fig. 5. Molecular probing pore size distribution based on the relative permeance of gases/vapour over the permeance of $\mathrm{He}$ at $200{ }^{\circ} \mathrm{C}$ as a function of the kinetic diameters (the broken line is a guide for eyes only).

$\mathrm{He}$ is essentially a non-adsorbing gas [49]. In the case of the separation of gas mixtures, the performance of gas permeation is significantly different from single gas permeation as reported by Yacou and co-workers [33]. Apart from fluid dynamic effects [52], competitive adsorption plays an important role in the gas transport through microporous membranes [53-55]. In other words, the stronger adsorbing gas or vapour (toluene in this work) preferentially adsorbs on surfaces and/or within the pore of the membranes. To further explain the transport of gas/vapours in this work, an idealized schematic is provided in Fig. 6. The percolation pathway shows He diffusing through the membrane. In pathway 2 , toluene diffuses through the amorphous cobalt oxide silica membrane, though it cannot pass the constrictions below $6.1 \AA$. Due to its strong adsorption, toluene may block some of the pore constrictions, thus impeding the diffusion of He. This is the reason for the observed fouling, leading to the decrease in He permeance under toluene exposure shown in Fig. 4a, and also after regeneration of the membrane, as toluene remained adsorbed on the membrane matrix. Pathway 3 allowed for the passage of both He and toluene, whilst the latter stayed adsorbed on the silica matrix. However, the aperture between the toluene molecule and the silica structure is still large enough to allow for He diffusion. The last pathway 4 shows a series of connected pores larger than $6.1 \AA$, thus forming a percolative pathway for the permeation of toluene. 


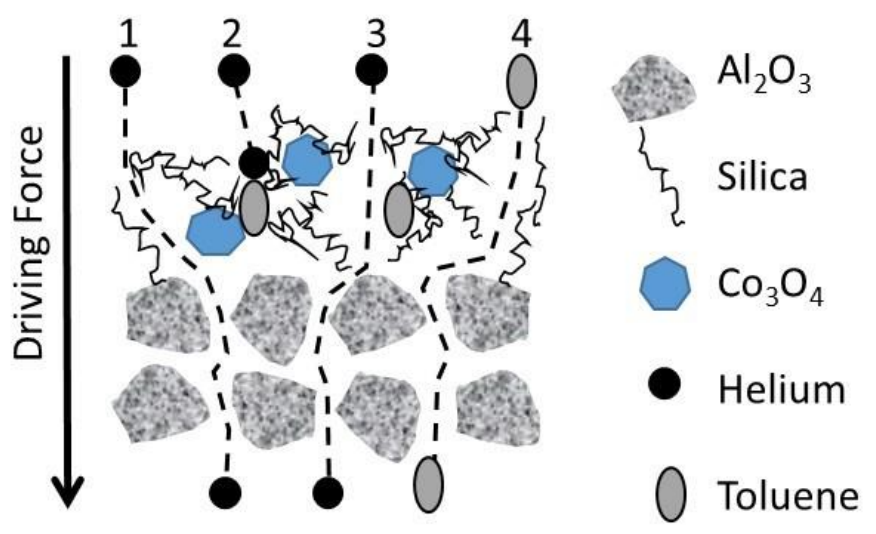

Fig. 6. Idealised schematic of gas pathways for the cobalt oxide silica film coated on alumina substrate.

\section{Conclusions}

The effect of toluene, as one of the components in gasification tars, on gas separation membranes was assessed in this study. Cobalt oxide silica membranes exhibiting molecular sieving features for single gas separation also delivered the same activated transport trend for simulated gas containing $\mathrm{He}$ and toluene. In other words, the permeation of the smaller atomic size gas He increased with temperature under the presence of the larger molecular size toluene vapour, whilst the permeance of the latter was essentially constant, with only a slight decrease at higher temperature. Toluene was able to diffuse through the membrane, though its permeance values were very low resulting in reasonably high He/toluene permselectivities of 57.7. Based on the permeation of several gases with different kinetic diameters, it was ascertained that the majority of the constrictions which control gas diffusion were below 3.2 $\AA$. The cobalt oxide silica matrix resulted in a pore size distribution with a number of percolation pathways which allowed for very low permeance values of larger atomic or molecular gases such as $\mathrm{CO}_{2}, \mathrm{~N}_{2}, \mathrm{Ar}$ and toluene vapour. A fraction of toluene was retained by the membrane, and its adsorption on the cobalt oxide silica matrix fouled the permeation of He. Toluene still remained partially adsorbed in the membrane even upon regeneration by heat treatment, which led to $\mathrm{He}$ permeance partially regaining its original values prior to toluene exposure. The stronger adsorbed 
toluene may have blocked some of the pores which would otherwise be accessible for He permeation, thus explaining the fouling effect. Therefore, the design of gas separation units and operations for biomass or coal derived syngas must consider the effect of toluene and other condensable gases in tars.

\section{Acknowledgement}

The authors would like to acknowledge financial support provided by the Australian Research Council (ARC) through Discovery Project Grant DP110101185. J. C. Diniz da Costa gratefully thanks the support given by the ARC Future Fellowship Program (FT130100405).

\section{References}

[1] A. Bauen, A.; G. Brown, G.; A.D. Hawkes, A.D.; M.A. Leach, M.A. (2006) Biomass Applications. Centre for Energy Policy and Technology, Imperial College London, [Online] Available from: http://www.eusustel.be/public/documents_publ/WP/WP3/Biomass\%20Applications\%20Report\% 20Final\%20ICEPT.pdf [Accessed 2nd June 2012]

[2] C.N. Hamelinck, A.P.C. Faaij, Future prospects for production of methanol and hydrogen from biomass, J. Power Sources 111 (2002) 1-22.

[3] S.D. Phillips, J. K. Tarud, M.J. Biddy, A. Dutta, Gasoline from Woody Biomass via Thermochemical Gasification, Methanol Synthesis, and Methanol-to-Gasoline Technologies: A Technoeconomic Analysis, Ind. Eng. Chem. Res. 50 (2011), 14226-14226.

[4] M. Ni, D.Y.C. Leung, M.K.H. Leung, K. Sumathy, An overview of hydrogen production from biomass, Fuel Proc. Technol. 87 (2006), 461-472.

[5] L. Devi, K.J. Ptasinski, F.J.J.G. Janssen, A review of the primary measures for tar elimination in biomass gasification processes, Biomass and Bioenergy 24 (2002), 125-140. 
[6] S.M. Kumar, G.M. Madhu, S. Roy, Fouling behaviour, regeneration options and on-line control of biomass-based power plant effluents using microporous ceramic membranes. Sep. Purif. Technol. 57 (2007) 25-36.

[7] F. Miccio, B. Piriou, G. Ruoppolo, R. Chirone, Biomass gasification in a catalytic fluidized reactor with beds of different materials. Chem. Eng. J. 154 (2009) 369-374.

[8] Y. Song, J. Xiang, S. Hu, D.M. Quyn, Y. Zhao, X. Hu, Y. Wang, C.-Z. Li, Importance of the aromatic structures in volatiles to the in-situ destruction of nascent tar during the volatile-char interactions, Fuel Proc. Technol. 132 (2015) 31-38.

[9] F. Pinto, R. N. André, C. Carolino, M. Miranda, Hot treatment and upgrading of syngas obtained by co-gasification of coal and wastes, Fuel Proc. Technol. 126 (2014) 19-29.

[10] D.J. Stevens, (2001) Hot gas conditioning: recent progress with larger-scale biomass gasification systems, National Renewable Energy Laboratory, U.S. Department of Energy Laboratory.

[11] A. Paethanom, S. Nakahara, M. Kobayashi, P. Prawisudha, K. Yoshikawa, Performance of tar removal by absorption and adsorption for biomass gasification, Fuel Proc. Technol. 104 (2012) 144-154.

[12] S. Mani, J.R. Kastner, A. Juneja, Catalytic decomposition of toluene using a biomass derived catalyst, Fuel Proc. Technol. 114 (2013) 118-125.

[13] F. Nestler, L. Burhenne, M.J. Amtenbrink, T. Aicher, Catalytic decomposition of biomass tars: The impact of wood char surface characteristics on the catalytic performance for naphthalene removal, Fuel Proc. Technol. 145 (2016)31-41.

[14] S. Smart, C.X.C.Lin, L. Ding, K. Thambimuthu,; J. C. Diniz da Costa, Ceramic Membranes for Gas Processing in Coal Gasification, Energy Env. Sci. 3 (2010) 268-278

[15] M.E. Ayturk, E.E. Engwall, Y.H. Ma, Microstructure analysis of the intermetallic diffusioninduced alloy phases in composite $\mathrm{Pd} / \mathrm{Ag} /$ porous stainless steel membranes, Ind. Eng. Chem. Res. 46 (2007) 4295-4306. 
[16] L. Yang; B.J. Yao, T. Takahashi, Study on production of $\mathrm{CH}_{4}$ in hydrogen purification with palladium-silver/ceramic composite membranes, Ind. Eng. Chem. Res. 49 (2010) 4377-4382.

[17] S. Tosti, A. Adrover,; A. Basile, V. Camilli, G. Chiappetta, V. Violante, Characterization of thin wall Pd-Ag rolled membranes, Int. J. Hydrog. Ener. 28 (2003) 105-112.

[18] J. Okazaki, T. Ikeda, D. A. Pacheco Tanaka, K. Sato, T/M. Suzuki, F/ Mizukami, An investigation of thermal stability of thin palladium-silver alloy membranes for high temperature hydrogen separation, J. Membr. Sci. (2011) 212-219.

[19] M. Kanezashi, M. Asaeda, Hydrogen permeation characteristics and stability of Ni-doped silica membranes in steam at high temperature, J. Membr. Sci. 271 (2006) 86-93.

[20] A. Darmawan, J. Motuzas, S. Smart, A. Julbe, J. C. Diniz da Costa, Temperature dependent transition point of purity versus flux for gas separation in Fe/Co-silica membranes, Sep. Purif. Technol. 151 (2015) 284-291.

[21] L. Liu, D. K. Wang, D. L. Martens, S. Smart, J.C. Diniz da Costa, Binary gas mixture and hydrothermal stability investigation of cobalt doped silica membranes, J. Membr. Sci. 493 (2015) $470-477$.

[22] M. Hong, S. Li, J.L. Falconer, R.D. Noble, Hydrogen purification using a SAPO-34 membrane, J. Membr. Sci.307 (2008) 277-283.

[23] H.B. Wang, X.L. Dong Y.S. Lin, Long-term hydrothermal and chemical stability properties of modified bilayer MFI zeolite membranes, J. Membr. Sci. 450 (2014) 425-432.

[24] H.B. Wang, Y.S. Lin, Synthesis and modification of ZSM-5/silicalite bilayer membrane with improved hydrogen separation performance, J. Membr. Sci. 396 (2012) 128-137.

[25] G. Barbieri, A. Brunetti, T. Granato, P. Bernardo, E. Drioli, Engineering Evaluations of a Catalytic Membrane Reactor for the Water Gas Shift Reaction, Ind. Eng. Chem. Res.44 (2005), $7676-7683$. 
[26] A. Basile, A. Criscuoli, F. Santella, E. Drioli, Membrane reactor for water gas shift reaction, Gas Sep. Purif. 10 (1996) 243-254.

[27] S. Tosti, A. Basile, G. Chiappetta, C. Rizzello, V. Violante, Pd-Ag membrane reactors for water gas shift reaction, Chem. Eng. J. 93 (2003) 23-30.

[28] S. Battersby, P. Werneck Teixeira, J. Beltramini, M. C. Duke, V. Rudolph and J. C. Diniz da Costa, An analysis of the Peclet and Damkohler numbers for dehydrogenation reactions using Molecular Sieve Silica (MSS) membrane reactors, Catalysis Today, 116 (2006) 12-17.

[29] Y. Zhang, Z. Wu, Z. Hong, X. Gu, N. Xu, Hydrogen-selective zeolite membrane reactor for low temperature water gas shift reaction Chem. Eng. J. 197 (2012) 314-321.

[30] R. Igi, T. Yoshioka, Y.H. Ikuhara, Y. Iwamoto, T. Tsuru, Characterization of Co-doped silica for improved hydrothermal stability and application to hydrogen separation membranes at high temperatures, J. Am. Ceram. Soc. 91 (2008) 2975-2981.

[31] S. Battersby, T. Tasaki, S. Smart, B. Ladewig, S. Liu, M.C. Duke, V. Rudolph, J. C. Diniz da Costa, Performance of cobalt silica membranes in gas mixture separation, J. Membr. Sci. 2009, 329, 91-98.

[32] D. Uhlmann, S. Liu, B.P. Ladewig J.C. Diniz da Costa, Cobalt-doped silica membranes for gas separation, J. Membr. Sci. 326 (2009) 316-321.

[33] C. Yacou, S. Smart, J.C. Diniz da Costa, Long term performance of a multi-tube cobalt oxide silica membrane at high temperatures for gas separation, Ener. Env. Sci. 5 (2012) 5820-5832.

[34] R.M. de Vos, H. Verweij, Improved performance of silica membranes for gas separation, J. Membr. Sci. 1998, 143 (1998) 37-51.

[35] H. R. Lee, T. Shibata, M. Kanezashi, T. Mizumo, J. Ohshita, T. Tsuru, Pore-size-controlled silica membranes with disiloxane alkoxides for gas separation, J. Membr. Sci. 383 (2011) 152-158.

[36] W. Torres, S.S. Pansare, J. G. Goodwin Jr., Hot gas removal of tars, ammonia, and hydrogen sulfide from biomass gasification gas, Cat. Rev. - Sci. Eng. 49 (2007), 407-456. 
[37] J. Mermelstein, M. Millan, N.P. Brandon, The impact of carbon formation on Ni-YSZ anodes from biomass gasification model tars operating in dry conditions, Chem. Eng. Sci. 64 (2009) 492500.

[38] T.A. Milne, R.J. Evans (1998). Biomass Gasifier "Tars": Their Nature, Formation and Conversion. National Renewable Energy Laboratory, U.S. Department of Energy Laboratory.

[39] J. Mermelstein, N.P. Brandon, M. Millan, The impact of steam on the interaction between biomass gasification tars and nickel based Solid Oxide Fuel Cell anode materials, Ener. Fuels 23, (2009) 5042-5048.

[40] D. Singh, E. Hernandez-Pacheco, P. N. Hutton, N. Patel, M.D Mann, Carbon deposition in an SOFC fueled by tar-laden biomass gas: A thermodynamic analysis, J. Power Sources 142 (2005) 194-199.

[41] E. Lorente, M. Millan N. Brandon, Use of Gasification Syngas in SOFC: Impact of Real Tar on Anode Materials, I. J. Hydrog. Ener. 37 (2012) 7271-7278.

[42] S. Smart, J.Vente, J.C. Diniz da Costa, High temperature $\mathrm{H}_{2} / \mathrm{CO}_{2}$ separation using cobalt oxide silica membranes, I. J. Hydrog. Ener. 37 (2002) 12700 - 12707.

[43] R. M. Barrer, Porous crystal membranes, J. Chem. Soc. Faraday Trans. 86 (1990) 1123-1130.

[44] R. S. A. de Lange, J. H. A. Hekkink, K. Keizer and A. J. Burggraaf, Formation and characterisation of supported microporous ceramic membranes prepared by sol-gel modification techniques, J. Membr. Sci. 99 (1995) 57-75.

[45] T.C. Golden, S. Sircar, Gas adsorption on silicalite. J. Colloid Interface Sci., 162 (1994) 183-188.

[46] L.V.C. Rees, P. Bruckner, J. Hampson, Sorption of $\mathrm{N}_{2}, \mathrm{Ch}_{4}$ and $\mathrm{CO}_{2}$ in silicalite-1, Gas. Sep. Purif. 5 (1991) 67-75.

[47] V. Boffa, J. E. ten Elshof, A. V. Petukhov, D. H. A. Blank, Microporous niobia-silica membrane with very low $\mathrm{CO}_{2}$ permeability, ChemSusChem 1 (2008) 437-443. 
[48] A. Darmawan, J. Motuzas, S. Smart, A. Julbe, J.C. Diniz da Costa, Binary iron cobalt oxide silica membrane for gas separation, J. Membr. Sci. 474(2015) 32-38.

[49] W. J. Bakker, L. J. P. van den Broeke, F. Kapteijn, J. A. Moulijn, Temperature dependence of one-component permeation through a silicalite-1 membrane, AIChE J. 43 (1997) 2203-2214.

[50] D.D. Do, D. Nicholson, H.D. Do, On the Henry constant and isosteric heat at zero loading in gas phase adsorption, J. Coll. Interf. Sci. 324 (2008) 15-24.

[51] M.C. Duke, S.J. Pas, A.J. Hill, Y.S. Lin, J.C. Diniz da Costa, Exposing the molecular sieving architecture of amorphous silica using positron annihilation spectroscopy, Adv. Funct. Mater. 18 (2008) 3818-3826.

[52] G. Ji, G. Wang, K. Hooman, S. Bhatia, J. C. Diniz da Costa, Simulation of binary gas separation through multi-tube molecular sieving membranes at high temperatures, Chem. Eng. J. 218 (2013) 394-404.

[53] R. Krishna, J.A. Wesselingh, The Maxwell-Stefan approach to mass transfer, Chem. Eng. Sci. 52 (1997) 861-911.

[54] J. van den Bergh, M. Mittelmeijer-Hazeleger, F. Kapteijn, Modeling permeation of $\mathrm{CO}_{2} / \mathrm{CH}_{4}$, $\mathrm{N}_{2} / \mathrm{CH}_{4}$, and $\mathrm{CO}_{2} /$ Air mixtures across a DD3R zeolite membrane, J. Phys. Chem. C 114 (2010) 9379-9389.

[55] R. Krishna, J.M. van Baten, Maxwell-Stefan modeling of slowing-down effects in mixed gas permeation across porous membranes, J. Membr. Sci. 383 (2011) 289-300. 